\title{
FOTOJORNALISMO NA MAGNUM IN MOTION: MIRADAS EM "THEATER OF WAR" PELO OLHAR DA TEORIA ATOR-REDE
}

Nadja Carvalho, Lorena Travassos 
FOTOJORNALISMO NA MAGNUM IN MOTION:

MIRADAS EM “THEATER OF WAR" PELO OLHAR DA TEORIA ATOR-REDE

Resumo: Estudamos, com amparo na Teoria Ator-Rede (TAR), o ensaio fotojornalístico "Theater of War" (2011), que integra o projeto Magnum in Motion (2004). Realizamos, portanto, neste artigo, uma descrição da rede de conexões entre atores humanos e não-humanos (actantes), relacionados ao exame de preceitos como simetria, tradução e caixa-preta, propostos na TAR e identificados nesse ensaio fotográfico.

Palavras chave: Fotojornalismo; Teoria Ator-Rede; Magnum in Motion

FOTOPERIODISMO EN MAGNUM IN MOTION:

MIRADAS EN EL “THEATER OF WAR” A TRAVÉS DE LA TEORÍA ACTOR-RED

Resumen: Referenciados en la Teoría Actor-Red (TAR), estudiamos el ensayo fotoperiodístico "Theater of War" (2011), que integra el proyecto Magnum in Motion (2004). En este artículo se presenta una descripción de la red de conexiones entre actores humanos y no humanos (actantes), relacionados al examen de los preceptos como simetría, traducción y caja-negra, propuesto en la TAR y identificados en este ensayo fotográfico.

Palabras clave: Fotoperiodismo; Teoría Actor-Red; Magnum in Motion

PHOTOJOURNALISM IN MAGNUM IN MOTION:

LOOKING "THEATHER OF WAR" THROUGH THE ACTOR-NETWORK THEORY

Abstract: We have studied, with some of the tools of the Actor-Network Theory (ANT), the photo-journalistic essay "Theater of War" (2011), which is part of the Magnum in Motion (2004). We have presented, thus, in this article, a description of this net of connections between human actors and not-humans (actants), related to the examination of principles such as symmetry, translation and black-box, proposed in ANT and identified in this photo essay.

Keywords: Photojournalism; Actor-Network Theory; Magnum in Motion 


\section{INTRODUÇÃO}

O surgimento da internet e sua posterior abertura para interesses comerciais na década de 80 deu início a trocas de dados. A necessidade de adaptação do conteúdo jornalístico na Web foi aos poucos tomando forma até chegar ao que conhecemos hoje. De início, as imagens que compunham os primeiros sites eram gifs animados ou ilustrações. Aos poucos as fotografias - com limitações de tamanho e de espaço devido à baixa velocidade de conexão - conseguiram chegar aos sites de uma forma similar à do jornalismo impresso.

Com a criação da banda larga, as imagens fixas e imagens em movimento passaram a ser mais viáveis, criando novas possibilidades para a utilização multimídia da fotografia enquanto produto jornalístico.

Os anos 1990 foram marcados por um grande desenvolvimento das novas tecnologias da comunicação e informação, modificando a produção e distribuição da imagem. Além disso, a internet se popularizou e os computadores ficaram bem mais acessíveis, facilitando o comércio e o consumo generalizado.

Em 1991 a Kodak lançou a primeira câmera digital, ainda com 1.3 megapixels. A Apple, dois anos depois, lançou uma câmera com valor mais acessível, marcando a popularização da fotografia digital.

Depois da criação de câmeras amadoras, foi a vez dos fotojornalistas passarem a ter uma câmera especialmente criada para sua profissão em 1994, graças à Kodak. $O$ produto nasceu em parceria com uma das agências mais famosas de fotojornalismo, a Associated Press (AP), que cobriu, em 1996, o primeiro evento com câmera digital, o SuperBowl XXX.

No início do século XXI, as agências de fotojornalismo realizaram a digitalização dos negativos de todos os arquivos e criaram bancos de dados para consulta de seus acervos na internet. Esse evento possibilitou a inserção de imagens em tempo real e a democratização de informações em todo o mundo. Ainda assim, várias agências importantes fecharam por não acompanhar os avanços tecnológicos, como a Gamma, Sygma e a Sypa (MERGIER apud MUNHOZ, 2002).

A Magnum Photos, cooperativa fotográfica formada em 1945, inicialmente por fotojornalistas já famosos àquela época, como Cartier Bresson, Robert Capa e Chim, acompanhou esse desenvolvimento da fotografia, exibindo além de bancos de dados com todos os negativos digitalizados, um acervo com as imagens e a apresentação de novos produtos, como a Magnum in Motion, que conta com ensaios compostos por fotografias em movimento acompanhadas 
de recursos audiovisuais.

É visível que está cada vez mais comum produzir imagens em aparelhos celulares e câmeras fotográficas, bastando uma resolução mínima para visualização das imagens nos diversos sites. Com a febre das redes sociais, e sites exclusivos para imagens como o Flickr (2004), o Tumblr (2007), o Instagram (2010), e o novo Pinterest (2011), qualquer usuário passou a ser um potencial produtor de imagens, sejam artísticas ou noticiosas.

Apesar dessa grande quantidade de imagens que circulam na rede, bancos de fotos jornalísticas são importantes na cobertura midiática por apresentarem imagens de qualidade e de procedência profissional.

No sentido de acompanhar essa evolução imagética do fotojornalismo na internet destacamos, neste artigo, o ensaio "Theater of War" da Magnum Photos por se tratar de um modelo hipermidiático de apresentação de imagens fotojornalísticas, com grande preocupação narrativa e plástica.

É importante ressaltar que esta agência fotográfica, teve seus representantes cobrindo graves conflitos mundiais entre nações, desde a invenção da câmera compacta de $35 \mathrm{~mm}$ e, ainda hoje, segue os seus princípios fotográficos ao acompanhar a evolução da fotografia e da internet, proporcionando, além de qualidade estética e técnica, inovações na própria apresentação da fotografia, seja ela analógica ou digital.

Segundo Bresson, um dos ilustres fundadores, "Magnum é uma comunidade de pensamento, uma qualidade humana compartilhada, a curiosidade sobre o que está acontecendo no mundo, um respeito pelo que está acontecendo e um desejo de transcrevê-lo visualmente"'.

\section{ENSAIO FOTOJORNALÍSTICO "THEATER OF WAR"}

Magnum in Motion é um projeto multimídia criado pela agência Magnum em 2004, que "reúne narrativas visuais para plataformas online e offline, incluindo projeções em museus, festivais e workshops" '. A narrativa da fotografia fixa introduz - no ambiente da Magnum - recursos audiovisuais, efeitos gráficos e de vídeos e conta com a interatividade que, atrelada ao aumento da

1 Disponível em: www.magnumphotos.com. Acesso em: 10 jul. 2012.

2 Os trabalhos podem ser acessados no site: www.magnuminmotion.com. Além de ensaios fotográficos jornalísticos, o projeto disponibiliza podcasts. 
velocidade da banda larga, dinamiza o cenário do fotojornalismo na internet.

Esses ensaios fotográficos não são meras apresentações sequenciais ou possuem um simples formato de cinema, eles contam com a presença de narrador (es), sons ambientes, músicas, vozes, relatos e efeitos de montagem (corte seco, imagem antiga, fade out etc.).

O projeto integra fotógrafos de várias partes do mundo, que passam por uma rígida seleção até serem aceitos como membros da agência. Os temas apresentados são variados, abordam desde a Segunda Guerra Mundial e a Guerra do Vietnã (as primeiras imagens realizadas com filme $35 \mathrm{~mm}$ ), até eventos atuais como a crise financeira na Grécia e o tsunami no Japão (imagens digitais).

Dentre os trabalhos que fazem parte da Magnum in Motion, observamos o ensaio "Theater of War" (Teatro da Guerra)3, com fotos de autoria de Moises Saman, que retrata os últimos dias da Líbia sob o domínio de Gaddafi em 2011. O propósito é identificar a rede de conexão entre os actantes humanos e não-humanos neste ensaio fotojornalístico, sob o recorte metodológico da Teoria Ator-Rede.

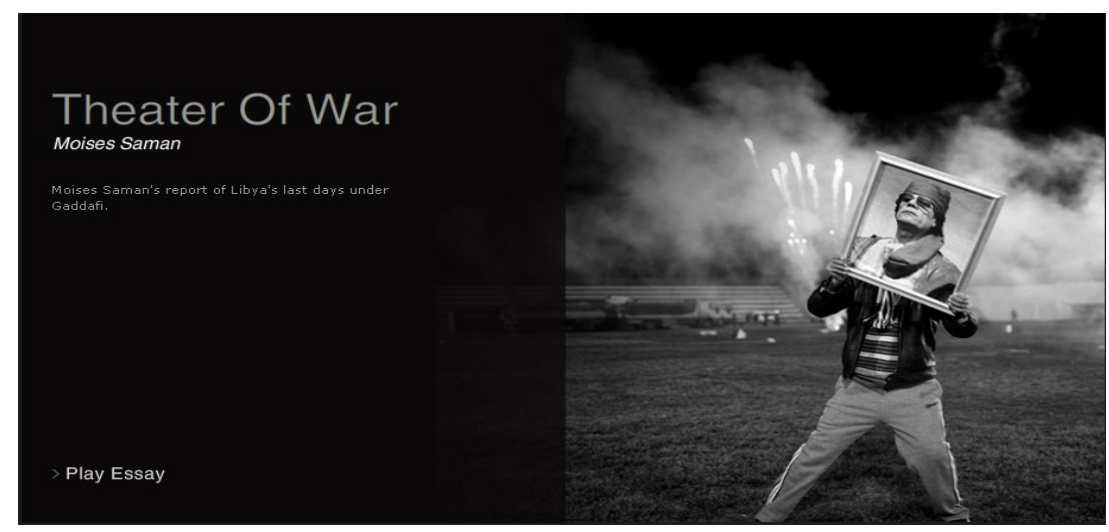

Figura 1- Página de abertura do ensaio fotográfico de Moises Saman Crédito: Reprodução

Na formação da equipe responsável pela confecção do ensaio "Theater of War", de Moises Saman, temos um diretor criativo responsável pela edição, duas pessoas responsáveis pela produção multimídia e os sons do local foram captados pelo próprio fotógrafo, já as sonoridades adicionais foram utilizadas

3 O ensaio "Theater of War" tem a duração 3 minutos e 27 segundos, ao final de sua exibição pode-se ler a biografia de Moises Saman e assistir a seus outros trabalhos fotográficos, também disponibiliza espaço para comentários. O ensaio pode ser acessado no link: http:// inmotion.magnumphotos.com/essay/theater-war.

4 Moises Saman nasceu em Lima, Peru. Ele foi convidado a participar da Magnum Photos em 2010 por indicação. Atualmente vive entre Cairo e Nova York. 
do banco Freesounds.

Entre as imagens vistas no ensaio há fotos de rua em preto e branco e a captura de imagens da TV libanesa. Logo no início da exibição surge uma narração em inglês, possivelmente do fotógrafo relatando a sua experiência no conflito, escutamos sons de bombas e gritos e uma trilha sonora de estilo clássico promove certo estado emocional, além da locução de noticiários da TV, tudo isso em meio a projeção de imagens dramáticas.

$\mathrm{Na}$ exibição as fotos e as imagens televisivas expressam tensão, são intercaladas de modo rápido, mostram cenas da cidade destruída, manifestantes em protesto, rebeldes fortemente armados, entrecortadas por persistentes aparições de Gaddafi. As imagens da TV libanesa em tom sépia têm efeito de filme antigo e na exibição do noticiário local o ditador fala ao microfone vestindo sua farda militar.

\section{COMANDOS DA TEORIA ATOR-REDE}

A Teoria Ator-Rede (TAR) foi criada na década de 80, por um grupo de antropólogos, sociólogos e engenheiros, dentre os quais estão Bruno Latour, Michel Callon e John Law. Embora a TAR seja considerada uma metodologia de pesquisa, ela alcançou um estatuto de teoria pela ambição do método e reconceitualização sistemática de práticas de pesquisa (WILKINSON apud FREIRE, 2004).

De acordo com Latour (1996), a melhor forma de explicar um evento é mostrar as conexões entre os elementos de uma rede. É por meio de um conjunto de pequenas histórias que estes elementos estabelecem conexões e se reúnem momentaneamente por ambivalências, formando um padrão, um remendo intelectual (LAW, 1997).

Dentre os principais preceitos da TAR destacam-se simetria, rede, ator, tradução e caixa-preta, apresentamos a seguir:

* Simetria - Tanto a natureza quanto a sociedade devem ser explicadas a partir de uma única interpretação (LATOUR, 1994). O social é definido como uma rede híbrida, constituída por atores humanos e não-humanos (o social e o técnico), de modo que as ações de ambos devem ser consideradas com a mesma importância. Na construção de softwares, por exemplo, o programador

5 Este ambiente possui grande acervo sonoro de acesso gratuito, muito popular entre os usuários que dependem desse recurso aplicado a suas produções audiovisuais. Disponível em: http://www.freesound.org. 
(humano) interage simultaneamente com o computador (não-humano) com a mesma importância para gerar o produto final.

* Rede - Relaciona-se a fluxos e circulações dos atores, que, uma vez envolvidos, interferem e sofrem interferências continuadas, portanto, as informações que circulam entre os atores estão sempre se modificando. Nesses termos essa rede é diferente da noção de rede cibernética, a qual se refere ao transporte de informações sem deformações ao longo de qualquer distância.

* Ator - O termo é utilizado para falar do humano e não-humano, ao contrário do uso na Sociologia, e por isso Latour (2001, p.346) emprega a expressão actante da semiótica greimasiana: "Uma vez que, em inglês, a palavra "actor" (ator) se limita a humanos, utilizamos muitas vezes "actant" (actante), termo tomado da semiótica para incluir não-humanos na definição".

* Tradução - O conceito de tradução (ou translação) vai além do significado de passar de uma língua pra outra, pois tem também como tarefa a transposição de um lugar para outro. Portanto para Latour (2000, p.194): “... transladar interesses significa, ao mesmo tempo, oferecer novas interpretações desses interesses e canalizar as pessoas para direções diferentes".

* Caixa-preta - É um fato ou artefato pronto, possuidor de estabilidade provisória, ou seja, sem controvérsias (dúvidas) acerca da rede formada. Na medida em que algo não funciona ou deixa de fazer sentido, surgem controvérsias que impõem a reabertura da caixa (LATOUR; WOOLGAR, 2000). Pesquisar é uma tomada de decisão diante da abertura de caixas-pretas de acordo com o surgimento de novas controvérsias.

\section{UMA APROXIMAÇÃO METODOLÓGICA}

O site Magnum in Motion (2004) é a nossa caixa-pretar. A controvérsia está na própria teatralidade da guerra, capturada no ensaio fotográfico "Theater of War".

O fluxo de atores envolvidos num ensaio fotográfico como este é gigan-

6 André Lemos recorda que o termo "actante” foi “criado por Lucien Tesnière e usado para designar o participante (pessoa, animal ou coisa) em narrativa literária. Para Greimas (1974), o actante é quem ou o que realiza a ação". Cf. Você está aqui! Mídias locativas e teorias “Materialidades da Comunicação e Ator-rede", 2010, p.7.

$7 \mathrm{O}$ site Magnum in Motion acolhe renomados profissionais do fotojornalismo e exibe excelentes trabalhos fotográficos com recursos audiovisuais, moldados pela evolução para nos emocionar com suas sonoridades e sutis movimentos. 
tesco, por exemplo, se observarmos o lado de quem é fotografado, vai desde a devastação, a desolação de um sujeito até a força da multidão. As interferências geradas pelas imagens circulam entre quem é visto e quem vê, indistintamente. É assim que o fotojornalismo vem sofrendo modificações de toda ordem e estão mudando nossa relação com essas imagens.

A expressão "teatro da guerra" atribuída à Guerra Civil da Líbia8 é imperativa pela força que os gestos retratados registram, pode-se ver a coragem dos protestos populares contra a ditadura de Gaddafí. A sequência de fotos intercala imagens de Gaddafi que persiste no Governo: uma foto de manifestante versus localidade arrasada; outra foto de protesto versus Gaddafi aparecendo na TV. Para cada foto antiGaddafi surge sempre outra próGaddafi: pode ser sua foto emoldurada, ele flagrado na multidão ou exibido na TV libanesa.

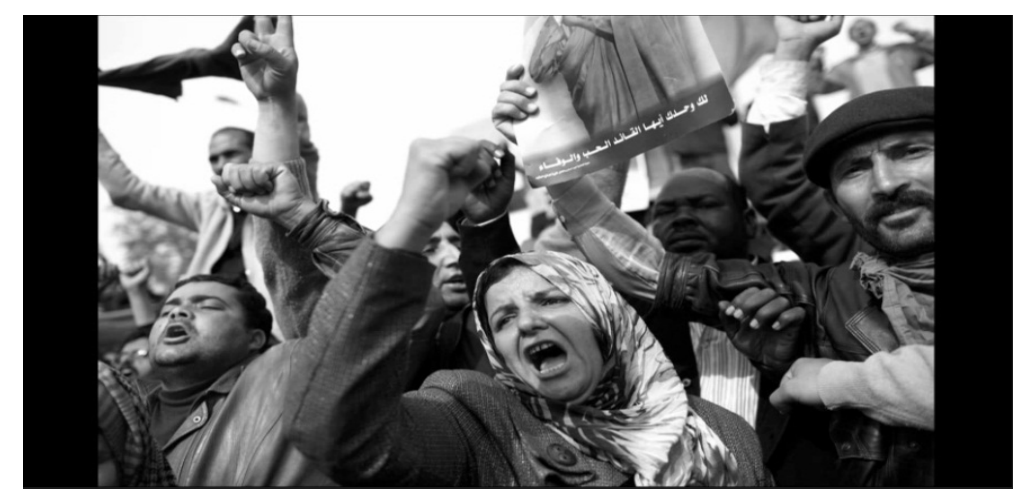

Figura 2 - Manifestantes flagrados na efervescência da multidão Crédito: Reprodução

Há traduções de imagens aleatórias e interpoladas por opositores e o ditador, trata-se de uma forma jornalística de narrar o drama de uma guerra, onde atores híbridos (fotografias, sonoridades, fotógrafo, fotografados e usuários) dialogam com intenções específicas de interesse artístico, comunicacional e histórico.

Existe uma guerra civil e outra guerra entre imagens no ensaio fotográfico de Moises Saman. O "teatro da guerra" tem na figura de Gaddafi o seu protagonista resistente. A imagem do ditador é traduzida para o ensaio de modo similar a sua encenação projetada na TV local sobre a Revolução Líbia.

8 A Guerra Civil na Líbia, ou ainda reconhecida como Revolução Líbia, foi iniciada em 13 de fevereiro de 2011, movida por reivindicações sociais e políticas que exigiram democracia, respeito pelos direitos humanos, distribuição de riquezas e redução da corrupção do Estado e suas instituições.

9 Muammar al-Gaddafi liderou a Líbia por 42 anos, era o chefe de Estado árabe no cargo há mais tempo, também conhecido pelos nomes Gaddafi, Kadhafi e Qaddafi. 
A imagem do poder midiático exercido pelo ditador reforça a dramaturgia do combate, cenas de protestos rebeldes e dos danos causados pelos ataques são exibidas lado-a-lado. A intransigência do governo Gaddafi promove inúmeras imagens da brutalidade repressora contra os manifestantes. $O$ ensaio captura apenas algumas, mas do modo como são ordenadas informam sobre a amplitude dos estragos igualmente provocados pelos rebeldes.

Mas há momentos na exibição do ensaio que a TV libanesa sai do ar e a imagem do ditador sofre abalos com a perda do sinal até desaparecer por completo ${ }^{10}$ e desse modo os chuviscos da TV fecham a tela. O que não significa dizer que outras cenas de dor, perdas e lutas não estejam pousando para novas fotos.

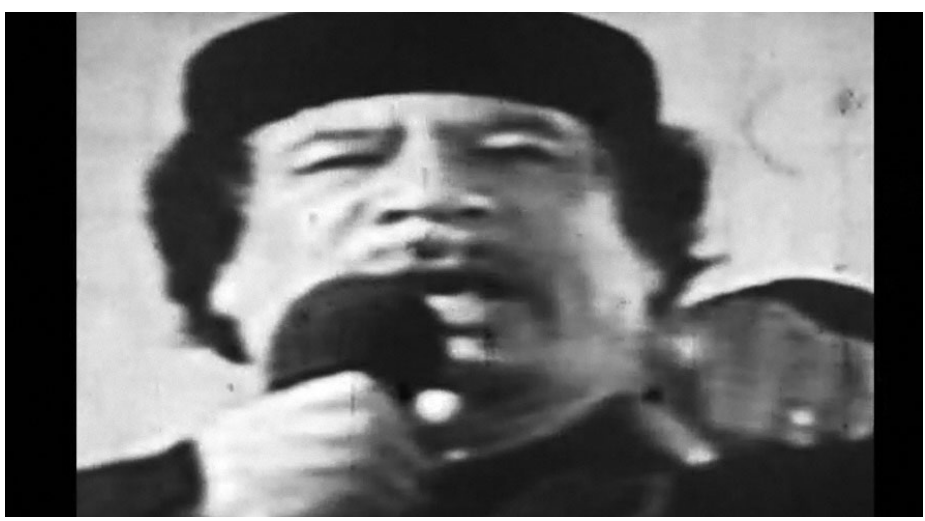

Figura 3 -Fotografia (metafoto) do Gaddafi na televisão Crédito: Reprodução

Diante de tais considerações e segundo a Teoria Ator-Rede, passamos a identificar os atores envolvidos nessa rede sociotécnica:

* Actantes humanos

a) Entre as pessoas fotografadas (quem é visto) estão: manifestantes, opositores, soldados, corpos de civis, Gadaffi e metafotos de Gadaffi (fotografia de foto).

b) Nas equipes de produção, edição, circulação e redistribuição (quem vê) temos: fotógrafo, diretor criativo, produtor multimídia, designer de navegação e suporte de usabilidade da Magnum Photos, o sujeito usuário, pesquisador, arquivista.

* Actantes não-humanos

10 Em 20 de outubro de 2011 ocorreu a morte de Muammar al-Gaddafi na cidade de Sirte e O Conselho Nacional de Transição líbio anunciou o fim da guerra, em 23 de outubro de 2011. 
a) Dispositivos tecnológicos do site: fotografia digital, software, banco de dados, servidores, interatividade, compartilhamento, aplicativo para rede social.

b) Artefatos e ambientes de rede que permitem o acesso do público: computador, dispositivo portátil 3G, internet fixa e móvel.

A natureza simétrica entre o ensaio e a realidade imediata da guerra, decorre de uma cobertura jornalística orquestrada sob olhares artístico, dramático, comunicacional, investigativo. Toda a captura do social incorpora invariavelmente as marcas técnicas advindas do ato fotográfico em si, por sua vez, sequenciadas pelo trabalho de seleção e ordenação exibido na edição final do material. Fica impossível não considerar aspectos de interação simétrica entre o social (realidade da guerra) e o técnico ("Theater of War”).

É compreensível, sob o ponto de vista da tradução, por sua vez, ocorrida entre a realidade objetiva e a fotografia, que ultrapassamos a mera translação entre códigos de linguagens, de uma "imagem objeto" extraída da realidade imediata para constituir uma imagem digital, impregnada pela contextualização de ritmos, paradas, sequências e sonoridades na edição. Na verdade, ocorre algo mais na noção de tradução, trata-se da herança da realidade objetiva transposta para o espaço ensaístico com toda aquela carga de tensão flagrada no embate, na correlação entre forças e no comportamento heroico da resistência, tais estados de sentidos estão presentes no ensaio fotojornalístico.

Enquanto existir resistência, a dúvida sobre quem sairá vitorioso persistirá, dessas incertezas objetivas nos fala muito a caixa-preta atribuída ao ensaio “Theater of War". Partindo do frenesi da sucessão de imagens para movimentos de aproximação e distanciamento, entrecortado por momentos mais lentos para logo em seguida saltar numa sequencia de imagens mais rápidas, este ensaio promove um contraste rítmico na exibição de imagens teatrais da guerra, exibicionistas ao usar o poder militar, a força das armas, o massacre brusco, e avassalador que almeja subjugar, derrotar o opositor.

\section{CONSIDERAÇÕES FINAIS}

Propomos a descrição do ensaio "Theater of War" para encontrarmos a rede de atores, com o intuito de examinar a controvérsia sobre a teatralidade que envolve a Guerra Civil na Líbia. Foram imagens de protestos, mortes, rebeldes armados, a internet, software e o próprio site da Magnum in Motion que, em trabalho conjunto, nos fizeram presenciar através de nosso computador, o conflito libanês. 
Os atores em rede (humanos e não-humanos) promovem uma simetria interativa entre o social e o técnico, permitindo uma tradução dialógica entre o espaço imediato e a obra fotojornalística. A partir daí tentamos nos apropriar do artefato pronto ensaístico, plástico e comunicacional, aqui tratado como caixa-preta, no sentido de identificar as controvérsias que se situam no espaço da guerra.

A controvérsia de natureza teatral presente no ensaio "Theater of War" nos permite, principalmente na aparição repetitiva de Gaddafi, presenciar a força oficial libanesa tentando encucar no seu opositor o sentido de derrota. O espectador, pela primeira vez diante do ensaio, compartilha de igual tensão sob o efeito da ameaça do ditador.

Como esse mapeamento dos actantes que compõem o ensaio, nos foi permitido observar a rede formada pelos diversos atores híbridos que interagem nessa hipermídia. Tendo em vista que a fotografia é mediada pela tecnologia desde o seu surgimento, consideramos esse aparato metodológico, o da Teoria Ator-Rede, de grande valor para entendermos os processos digitais do fotojornalismo na contemporaneidade.

\section{REFERÊNCIAS}

BENJAMIN, Walter. Pequena história da fotografia. In: Magia e técnica, arte e política. São Paulo: Brasiliense, 1985.

FREIRE, Leticia de Luna. Seguindo Bruno Latour: notas para uma antropologia simétrica. Revista Comum, Rio de Janeiro, v. 11, n.26, p. 46-65, 2006.

KOSSOY, Boris. Fotografia e história. 2 ed. São Paulo: Ateliê editorial, 2001.

LATOUR, Bruno. Jamais fomos modernos: ensaio de antropologia simétrica. Rio de Janeiro: Editora 34, 1994.

Manantial, 2008.

. Reensemblar lo social: una introducción a la teoria del actor-red. Buenos Aires:

LATOUR, B.; WOOLGAR, S. Ciência em ação: como seguir cientistas e engenheiros sociedade afora. São Paulo: UNESP, 2000.

EDUSC, 2001.

. A esperança de Pandora: ensaios sobre a realidade dos estudos científicos. Bauru:

LAW, J. Notas sobre a Teoria Ator-Rede: ordenamento, estratégia, e heterogeneidade, 1997. Trad. Fernando Manso. Disponível em: http://www.necso.ufrj.br/. Acesso em: 2 jul. 2012.

LEMOS, André. Você está aqui! Mídia Locativa e teorias "Materialidades da Comunicação" e "Ator -Rede", In: Revista Comunicação e Sociedade, São Bernardo do Campo, v.32, n. 54, p. 5-29, 2010. 
MUNHOZ, Paulo. Estágios do desenvolvimento do fotojornalismo na Internet. Revista Diálogos \& Ciência, Salvador, v. 5, n. 11, p. 1-5, 2007.

MUZI, Daniela. Tecnologias e materialidades da comunicação no documentário: atores humanos e não humanos na obra de Eduardo Coutinho. Rio de Janeiro: Universidade do Estado do Rio de Janeiro. Dissertação, Mestrado, 2011.

RECEBIDO EM: 09/11/12

ACEITO PARA PUBLICAÇÃO: 07/12/12

\section{Nadja Carvalho}

Professora do Programa de Pós-Graduação em Comunicação da UFPB. Doutora em Comunicação e Semiótica pela Pontifícia Universidade Católica de São Paulo (PUC/SP-2002). Experiência em Comunicação Visual e Mídia Digital, atuando nos campos da semiótica, humor e poética; Movie-clip (charges animadas); HQtrônica (histórias em quadrinhos eletrônicas) e, mais recentemente, Minimídia celular (pequenas mídias móveis).

\section{Lorena Travassos}

Mestranda do Programa de Pós-Graduação em Comunicação da UFPB, fotógrafa, tem pesquisa com ênfase nos novos processos fotográficos, filosofia e teoria da imagem. 